\title{
Relevance of 3D Cholangiography and Transient Elastography to Assess Cystic Fibrosis-Associated Liver Disease?
}

\author{
C. Lemaitre, ${ }^{1}$ S. Dominique ${ }^{2}$ E. Billoud, ${ }^{3}$ M. Eliezer, ${ }^{4}$ H. Montialoux ${ }^{1}$ M. Quillard, ${ }^{5}$ \\ G. Riachi, ${ }^{1}$ E. Koning, ${ }^{4}$ H. Morisse-Pradier, ${ }^{2}$ G. Savoye, ${ }^{1,6}$ C. Savoye-Collet, ${ }^{4}$ and O. Goria ${ }^{1}$ \\ ${ }^{1}$ Department of Gastroenterology and Hepatology, Rouen University Hospital, Rouen, France \\ ${ }^{2}$ Department of Pneumology, Adult Cystic Fibrosis Centre, Rouen University Hospital, Rouen, France \\ ${ }^{3}$ Department of Gastroenterology, Le Havre General Hospital, Le Havre, France \\ ${ }^{4}$ Department of Radiology, Rouen University Hospital, Rouen, France \\ ${ }^{5}$ Clinical Biology Institute, Rouen University Hospital, Rouen, France \\ ${ }^{6}$ INSERM U1073, Institute for Research and Innovation in Biomedicine, Faculty of Medicine, University of Rouen, Rouen, France
}

Correspondence should be addressed to C. Lemaitre; caroline.lemaitre@chu-rouen.fr

Received 16 September 2015; Revised 25 May 2016; Accepted 2 June 2016

Academic Editor: Christophe Leroyer

Copyright (C) 2016 C. Lemaitre et al. This is an open access article distributed under the Creative Commons Attribution License, which permits unrestricted use, distribution, and reproduction in any medium, provided the original work is properly cited.

Background. Cystic fibrosis-associated liver disease (CFLD) is a major cause of death. The objective of our retrospective study was to describe the relevance of magnetic resonance imaging (MRI) and liver stiffness measurement (LSM) for CFLD evaluation. Methods. All cystic fibrosis adult patients evaluated by MRI and LSM were included. MR signs of portal hypertension (PHT), dysmorphia, or cholangitis were collected and LSM expressed in $\mathrm{kPa}$ and Metavir. Results. Of 25 patients, 52\% had abnormal MRI. Median LSM was $5.7 \mathrm{kPa}$ (3.4-9.9). Three patients had F2 score and one had F3 score. In patients with PHT, LSM was 7.85 kPa (3.7-9.9) compared to 5 (3.4-7.5) in others, $p=0.02$. In patients with abnormal liver function tests, $50 \%$ had increased LSM ( $\geq$ F2), whereas $94 \%$ with normal tests had normal LSM $(p=0.04)$. Seven patients had abnormal MRI despite normal ultrasonography. Conclusions. MRI and LSM provide useful information on CFLD and may help to screen patients with PHT.

\section{Background}

Cystic fibrosis-associated liver disease (CFLD) leads to important morbidity and mortality [1]. Hepatobiliary disease is the most common nonpulmonary cause of mortality in cystic fibrosis (the third after pulmonary disease and transplant complications). Its prevalence is estimated to involve around one-third of patients regardless of diagnosis methods used (clinical, biochemical, or radiological) and may rise to $72 \%$ in autopsy series $[2,3]$. This difference is explained by the definition of CFLD. In fact, CFLD definition is controversial. Usually, for diagnosis, two abnormalities, clinical (hepatomegaly, splenomegaly) or biological (elevated liver function tests without other causes, in 3 determinations, during a period of 12 months) or US's signs (liver involvement, portal hypertension, and biliary abnormalities), seem necessary for diagnosis [4].
Dysfunction of the CFTR protein located on the apical pole of the cholangiocyte membranes $[5,6]$ is responsible for impaired bile transport [7] and focal duct obstruction [8]. Production of proinflammatory chemokines by cholangiocytes, such as Tumor Growth Factor $\beta$, induces hepatic stellate cell chemotaxis and proliferation. This inflammatory reaction is responsible for primary sclerosing cholangitislike cholangiopathy, by the production of extracellular matrix $[8,9]$.

Early recognition is important for diagnosis of fibrosis and prevents its complications, especially portal hypertension (PHT). Tools available for diagnosis of cystic fibrosisassociated liver disease (CFLD) are scarce [10]. Currently annual liver function test (LFT) and ultrasonography (US) are proposed. Colombo et al. proposed CFLD diagnosis criteria, including clinical, biochemical, US, and histological criteria [2]. These criteria have not been validated and have low 
sensitivity and specificity [11]. Liver biopsy (LB) is an invasive procedure, which is potentially dangerous in CF patients with respiratory weakness and lung distension. Moreover, the focal nature of fibrotic lesions in the initial phases of the disease may lead to inadequate estimation of fibrosis [12]. Lewindon et al. recommended a dual pass $\mathrm{LB}$, to improve the result of CFLD diagnosis to $21 \%$ [13]. However, LB is associated with risks, which increase with the number of passes [14]. Furthermore, it is currently difficult to predict which patients will develop cirrhosis with complications. So, LB indications are limited to ruling out severe liver disease in settings of evaluation prior to lung transplantation. Recently, noninvasive tests have been developed to evaluate liver diseases and especially fibrosis [15]. Hepatic and biliary magnetic resonance imaging (MRI) allows extensive exploration of the liver and biliary tract whereas transient elastography is able to estimate fibrosis. This method of fibrosis evaluation has been proved to be reliable in many liver diseases including mainly biliary tract abnormalities such as primary sclerosis cholangitis [16].

The objective of the present cohort study was to describe the relevance of magnetic resonance cholangiography and transient elastography for assessment of cystic fibrosisassociated liver disease in adult patients.

\section{Methods}

2.1. Study Subjects and Design. A retrospective one-year cross-sectional cohort study was performed in our cystic fibrosis reference centre at Rouen University Hospital. All adult patients with CF, investigated by hepatobiliary MRI and by transient elastography for liver stiffness measurement (LSM) between July 2009 and July 2010, were included. We excluded patients in whom CFTR-related disorder was limited to one-organ dysfunction (i.e., congenital bilateral absence of vas deferens). Clinical and genetic characteristics were retrospectively collected from patient charts and included meconium ileus, pancreatic insufficiency, diabetes mellitus, body mass index, $\Delta$ F508 genotype, alcohol intake (according to the World Health Organisation's definition [17]), ursodeoxycholic acid (UDCA), antibiotics, and antifungal treatments. We also collected biochemical analysis (LFT, platelet counts, prothrombin time, albumin, and renal function) and routine abdominal US results including hepatic dysmorphia or PHT signs. In all patients with abnormal LFT (any test $>$ twice the normal values), additional workup was available including search for hepatitis B, hepatitis C, ferritin, transferrin saturation, and fasting lipid profile. Pulmonary function was collected, including forced expiratory volume.

2.2. LSM by Transient Elastography. LSM by transient elastography was measured by Fibroscan ${ }^{\circledR}$ (Echosens ${ }^{\circledR}$, Paris, France, size M). Ten measurements were taken in 3 different sites in the hepatic right lobe through an intercostal space, with the patient's right arm in maximal abduction. The results are expressed as a mean of 10 valid measurements. To be valid, the measurements had to meet two conditions: (i) an adequate success rate defined as the number of valid measurements divided by the total number of measurements performed greater than or equal to $60 \%$ and (ii) an interquartile range (IQR) of less than $30 \%$ of the median to take into account the variability of valid measurements. Results were expressed in kilopascal $(\mathrm{kPa})$ and a correspondence table to the Metavir scoring system was used based on previous study of transient elastography in chronic biliary disease [16]. Metavir F0-F1 score corresponded to LSM of $\geq 7.2 \mathrm{kPa}$, and $\mathrm{F} 2, \mathrm{~F} 3$, and F4 corresponded to $\geq 7.3 \mathrm{kPa}, 9.8 \mathrm{kPa}$, and $17.3 \mathrm{kPa}$, respectively [16].

2.3. Biliary and Hepatic Magnetic Resonance Imaging. MRI examination was performed with 1.5 Tesla (Philips Achieva, Philips Medical Systems, Best, Netherlands) using a torso phased-array coil. No particular preparation was required. Fasting 4 hours before was required. All patients were placed in supine position with the upper abdomen centred on the coil. The following sequences were performed: (1) T1weighted sequence, axial image (TR $183 \mathrm{~ms}$, TE $2.3 \mathrm{~ms}$, FOV $70 \mathrm{~mm}$, slice thickness $7 \mathrm{~mm}$, angle $55^{\circ}, 152 \times 432$ ); (2) T2weighted sequence, axial SPAIR (TR $4459 \mathrm{~ms}$, TE $70 \mathrm{~ms}$, FOV $76 \mathrm{~mm}$, slice thickness $6 \mathrm{~mm}$, angle $90^{\circ}, 218 \times 320$ ); (3) T2-weighted sequence, axial HR (TR $1573 \mathrm{~ms}$, TE $100 \mathrm{ms,}$ FOV $79 \mathrm{~mm}$, slice thickness $7 \mathrm{~mm}$, angle $\left.90^{\circ}, 341 \times 560\right)$; (4) T2-weighted sequence diffusion 2b (TR $1489 \mathrm{~ms}$, TE $59 \mathrm{~ms}$, FOV $90 \mathrm{~mm}$, slice thickness $6 \mathrm{~mm}, 92 \times 67$ ); (5) 3D MR cholangiogram (TR $1341 \mathrm{~ms}$, TE $574 \mathrm{~ms}$, FOV $100 \mathrm{~mm}$, slice thickness $2.4 \mathrm{~mm}$, angle $90^{\circ}, 221 \times 560$ ); (6) in and out phase sequence (TR $175 \mathrm{~ms}$, TE $2.3 \mathrm{~ms}$ (in), $4.8 \mathrm{~ms}$ (out), FOV $40^{\circ}$, slice thickness $4 \mathrm{~mm}$, angle $\left.80^{\circ}, 224 \times 192\right)$. Abdominal radiologists (CSC and $\mathrm{EK}$ ) reviewed all MRI results blinded to clinical or biochemical parameters and reached decisions by consensus. Native and 3D MIP (maximum intensity projection) reconstructions were analyzed on a workstation (EasyVision, Philips Medical Systems, Best, Netherlands). The following items were studied for each patient using a standardized scale: atrophy of either right or left hepatic lobe and/or hypertrophy of the caudate lobe, marked lobulations of liver surface, first-segment hypertrophy, splenomegaly (long axis superior to $12 \mathrm{~cm}$ ), portal vein dilatation (diameter superior to $12 \mathrm{~mm}$ ), splenic vein dilatation, intrahepatic or extrahepatic biliary duct irregularity (segmental strictures and dilatations), ascites, and steatosis. Pancreatic patterns were also noted: partial or total pancreatic fatty involution, Wirsung duct irregularity, and pancreatic cysts.

PHT was diagnosed in the presence of one or more of these signs: collateral circulation, portal vein dilatation, splenic vein dilatation, or splenomegaly. Hepatic dysmorphia was diagnosed in the presence of one or more of these signs: atrophy of either right or left hepatic lobe, hypertrophy of the caudate lobe, marked lobulations of liver surface, and firstsegment hypertrophy.

We studied the results of LSM and hepatic MRI, according to the results of LFT or US.

2.4. Statistical Analysis. Statistical analysis was conducted using SAS software version 9.3 (SAS Institute, Cary, NC, USA). SI units were used for all laboratory values with data summarized using mean \pm standard deviation (SD) 


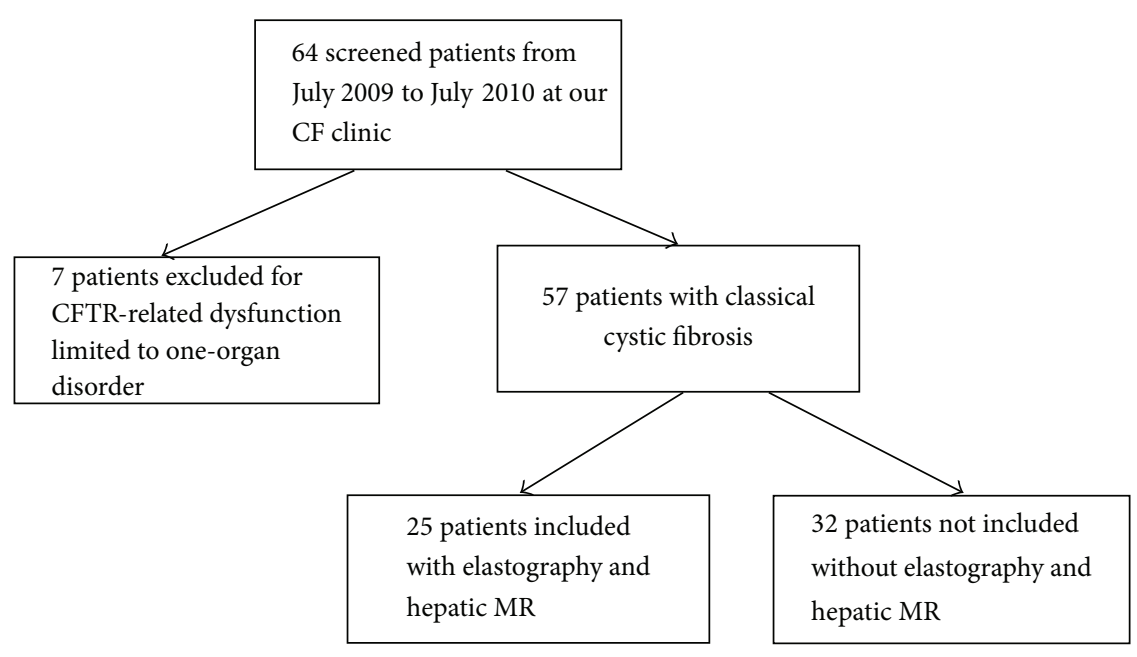

FIGURE 1: Flow chart for inclusion in our study.

for continuous variables and number (\%) for all recorded categorical variables describing the study population.

LSM are expressed in $\mathrm{kPa}$ as median (IQR). Student's $t$ test was used to compare continuous variables between CF patients included and the whole CF cohort as appropriate, whereas categorical variables were compared using chisquare test.

Regarding concordance between study methods, agreement was evaluated by Kappa-test: 1 = perfect agreement, $1-$ $0.8=$ almost perfect agreement, $0.8-0.6=$ good agreement, 0.6-0.2 = moderate and fair agreement, and less than 0.20 $=$ slight agreement. To assess the diagnostic performance of LSM for prediction of PHT, the area under the receiver operating curve (AUROC) was calculated. Optimal LSM for prediction of PHT was identified by estimating sensitivity and specificity for various cut-offs.

Prevalence of abnormalities in MRI and LSM was compared regarding the presence or not of LFT and/or US abnormalities using chi-square test and Fisher's exact test.

All statistical significance was taken at 95\% confidence interval and $p$ value of less than 0.05 was considered as significant.

\section{Results}

3.1. Patients' Characteristics. Of 64 adult CF patients followed up at our tertiary care center, 25 were included (Figure 1). Demographic characteristics at baseline are summarized in Table 1. Characteristics of studied patients were not statistically different compared to our whole CF population. However, patients included were more likely to receive UDCA ( $40 \%$ versus $13 \%, p=0.028$ ) and antifungal drugs (76\% versus $31 \%, p<0.001)$ than nonincluded patients. Only 6 patients included in our study had abnormal LFT and/or US abnormalities (hepatic dysmorphia, PHT signs, and gallstones). FEV1 median is 67.6\% (50.4-84.8) in our 25 patients versus $71.2 \%(47.5-94.9)$ in the whole CF cohort $(p=0.33)$.

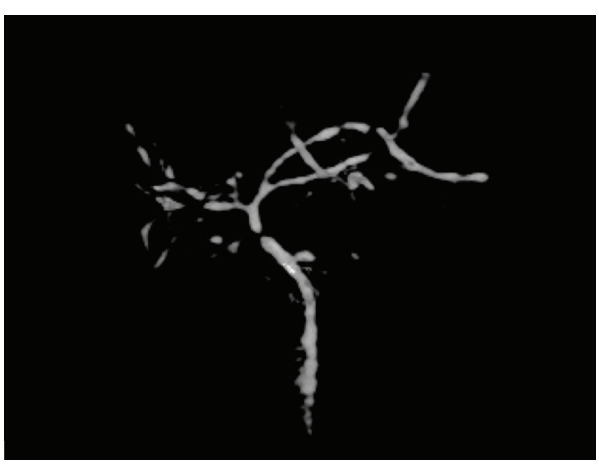

FIGURE 2: 3D MRI cholangiogram shows intrahepatic and extrahepatic biliary duct irregularity, with choledochus stenosis.

3.2. MRI Results (Table 2). At least one abnormal MRI sign was found in 13 patients (52\%). We evidenced isolated hepatic dysmorphia, PHT, and isolated biliary tract abnormality in 3 patients (12\%), 5 patients $(20 \%)$, and 1 patient (4\%), respectively (Figure 2). Two patients combined hepatic dysmorphia, PHT signs, and biliary abnormalities (8\%). We found no liver steatosis or ascites in our series. Other MRI abnormalities found were pancreatic cysts in 10 patients (40\%) and Wirsung duct irregularity in 5 patients $(20 \%)$. Partial and total pancreatic fatty involution were found in 5 patients (20\%) and 19 patients (76\%), respectively. Two patients had gallstones without complications.

3.3. LSM Results. Of the 25 patients included, 2 were excluded due to success rate of less than $60 \%$ in transient elastography, with mismatch between sites of measurement. Taking into account the median of the 10 highest measures for each patient, the median value of LSM was $5.7 \mathrm{kPa}(3.4-9.9)$ in this cohort. Fibrosis scores were as follows: F0-F1 in 19 patients $(82.6 \%), \mathrm{F} 2$ in 3 patients (13\%), and F3 in 1 patient $(4.3 \%)$, and no patient reached the F4 stiffness threshold. All patients with a score greater than or equal to F2 were men $(p=0.019)$. 
TABLE 1: Patients' characteristics at study enrolment.

\begin{tabular}{|c|c|c|c|}
\hline Patients' characteristics & $\begin{array}{l}\text { Studied patients } \\
n=25(\%)\end{array}$ & $\begin{array}{c}\text { Whole CF cohort } \\
n=57(\%)\end{array}$ & $p$ \\
\hline Gender (male/female) & 0.46 & 0.50 & 1 \\
\hline Median age (yrs [min.--max.]) & $25[18-43]$ & $30.1[18-62]$ & 0.12 \\
\hline Meconium ileus & $4(16 \%)$ & $12(21 \%)$ & 0.76 \\
\hline Pancreatic insufficiency & $22(88 \%)$ & $49(85.9 \%)$ & 1 \\
\hline \multicolumn{4}{|l|}{ Genotype } \\
\hline$\Delta \mathrm{F} 508-\Delta \mathrm{F} 508$ & $11(44 \%)$ & $20(35.1 \%)$ & 0.46 \\
\hline$\Delta \mathrm{F} 508$, other mutations & $12(48 \%)$ & $31(54 \%)$ & 0.63 \\
\hline 2 other mutations & $1(4 \%)$ & $6(10 \%)$ & 1 \\
\hline Medium BMI (kg/m² [min.-max.]) & $19.3[17.0-29.4]$ & $21.4[17.0-32.9]$ & 0.11 \\
\hline Alcohol & $0(0 \%)$ & $0(0 \%)$ & 1 \\
\hline Diabetes mellitus & $4(16 \%)$ & $13(22.8 \%)$ & 0.57 \\
\hline Dyslipidemia & $1(4 \%)$ & $1(1.7 \%)$ & 0.52 \\
\hline Antibiotics & $17(68 \%)$ & $41(72 \%)$ & 0.79 \\
\hline Antifungal drugs & $19(76 \%)$ & $29(51 \%)$ & 0.051 \\
\hline UDCA treatment & $10(40 \%)$ & $14(24 \%)$ & 0.19 \\
\hline Creatinine clearance $\geq 70 \mathrm{~mL} / \mathrm{min}$ & $25(100 \%)$ & $57(100 \%)$ & 1 \\
\hline FEV1 (\%) & $67.6 \%[50.4-84.8]$ & $71.2 \%[47.5-94.9]$ & 0.33 \\
\hline
\end{tabular}

BMI: body mass index; UDCA: ursodeoxycholic acid.

TABLE 2: MRI results.

\begin{tabular}{|c|c|c|c|}
\hline Diagnosis in MRI & Specific abnormalities in MRI & $N$ & Total number (\%) \\
\hline Abnormal MRI & & & $13(52 \%)$ \\
\hline \multirow{2}{*}{ Hepatic dysmorphia } & Included lobulation of liver surface & 3 & \multirow{2}{*}{$3(12 \%)$} \\
\hline & Included first-segment hypertrophy & 0 & \\
\hline \multirow{3}{*}{ Portal hypertension } & Included splenomegaly & 5 & \multirow{3}{*}{$5(20 \%)$} \\
\hline & Included portal vein dilatation & 2 & \\
\hline & Included splenic vein dilatation & 1 & \\
\hline \multirow{2}{*}{ Isolated biliary abnormalities } & Intrahepatic & 1 & \multirow{2}{*}{$1(4 \%)$} \\
\hline & Extrahepatic & 0 & \\
\hline $\begin{array}{l}\text { Hepatic dysmorphia and portal } \\
\text { hypertension }\end{array}$ & & 0 & $0(0 \%)$ \\
\hline $\begin{array}{l}\text { Hepatic dysmorphia and biliary } \\
\text { abnormalities }\end{array}$ & $\begin{array}{l}\text { Included lobulation of liver surface and } \\
\text { intrahepatic abnormalities }\end{array}$ & 1 & $1(4 \%)$ \\
\hline $\begin{array}{l}\text { Portal hypertension and biliary } \\
\text { abnormalities }\end{array}$ & $\begin{array}{l}\text { Included portal vein hypertrophy and } \\
\text { intrahepatic abnormalities }\end{array}$ & 1 & $1(4 \%)$ \\
\hline $\begin{array}{l}\text { Hepatic dysmorphia, portal } \\
\text { hypertension, and biliary } \\
\text { abnormalities }\end{array}$ & $\begin{array}{l}\text { Included splenomegaly, lobulation of liver } \\
\text { surface, first-segment hypertrophy, and } \\
\text { intrahepatic and extrahepatic } \\
\text { abnormalities }\end{array}$ & 2 & $2(8 \%)$ \\
\hline Normal MRI & & & $12(48 \%)$ \\
\hline Total & & & $25(100 \%)$ \\
\hline
\end{tabular}

In patients with evidence of hepatic disease obtained by any other means, mean LSM was $6 \mathrm{kPa}(3.4-9.9)$, versus $4.9 \mathrm{kPa}$ (3.9-7.3) in patients without CFLD $(p=0.3)$.

In patients with evidence of PHT, mean LSM was $7.85 \mathrm{KPa}$ (3.7-9.9) compared to $5 \mathrm{kPa}(3.4-7.5)$ in patients with no evidence of PHT $(p=0.02)$. The AUROC for LSM predicting the presence of PHT was 0.80 [95\% CI $=[0.53 ; 1.0]]$ (Figure 3). LSM cut-off of $6.3 \mathrm{kPa}$ predicted the presence of PHT with $66.7 \%$ sensitivity, 94.1 specificity, 80.0 positive predictive value, and 88.9 negative predictive value. No patient with 


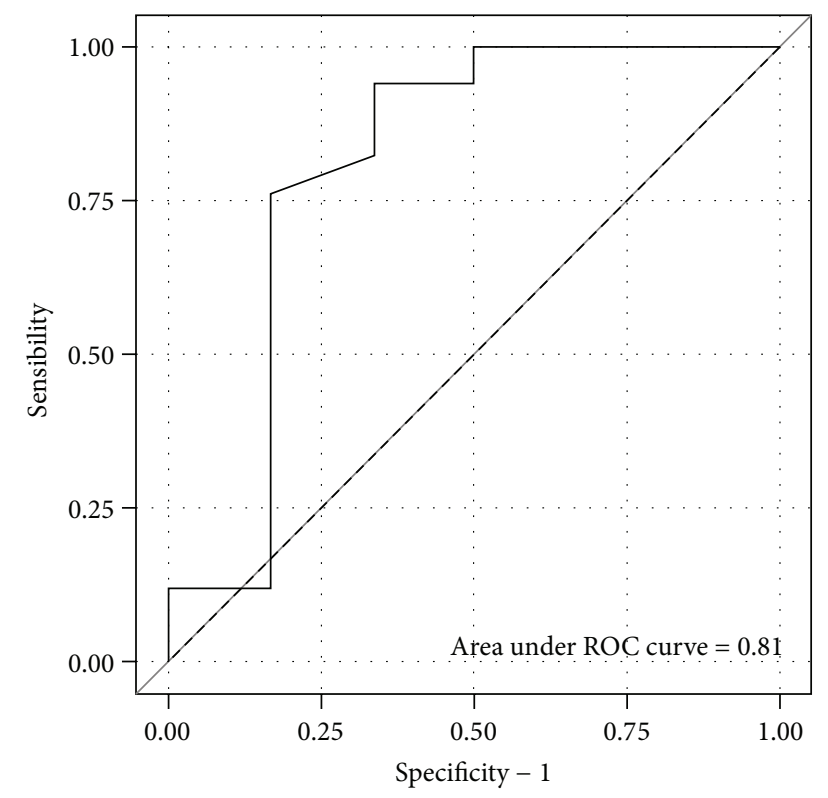

FIGURE 3: ROC curve for liver stiffness measurement predicting the presence of portal hypertension.

PHT on imaging technique had bleeding prior to or during the study. Endoscopic evaluation was available for 2 patients with PHT: one was normal, and the second showed PHT gastropathy.

3.4. MRI and LSM Concordance. For diagnosis of CFLD, there was low concordance between transient elastography and MRI $(k=0.25)$. Kappa values observed were 0.5 for PHT assessment with agreement reaching the threshold of "moderate" and 0.24 for fibrosis.

3.5. Magnetic Resonance Cholangiography and Liver Elastography Results according to Routine Testing Status. With a median of 2 LFT per patient, only 6 patients had at least 1 abnormal LFT (28\%) during the study period.

Of the $60 \%$ of patients with routine US, 5 had abnormal US findings: 3 patients with signs of PHT and 2 with gallstones without evidence of any complications. All patients with abnormal US findings had at least 1 abnormal LFT.

FEV1 was not different between patients with or without $\operatorname{PHT}(p=0.59)$.

Table 3 summarizes LSM and MRI findings according to routine status testing (LFT and US). Of the 6 patients with abnormal LFT and US, 50\% had significant increase in liver stiffness $(\geq F 2)$, whereas $94 \%$ of the 17 patients with normal routine status testing had normal LSM, $p=0.04$.

\section{Discussion}

Noninvasive assessment of CFLD is an emerging topic with important implications [15]. The present study reports a combined approach using MRI and transient elastography for liver stiffness evaluation in adults with CF. We found overall prevalence of $52 \%$ for MRI abnormalities including
TABLE 3: Results of LSM and MRI according to the results of liver function tests and abdominal ultrasonography.

\begin{tabular}{lcc}
\hline & LFT or US abnormalities & No $(n=17)$ \\
Yes $(n=6)$ & $94 \%$ F0-F1 $(n=16)$ & 0.04 \\
\hline $50 \%$ F0-F1 $(n=3)$ & $6 \% \geq$ F2 $(n=1)$ & \\
$50 \% \geq$ F2 $(n=3)$ & $58.8 \%$ normal MRI $(n=10)$ & 0.37 \\
\hline $33.3 \%$ normal MRI $(n=2)$ & $41.2 \%$ abnormal MRI $(n=7)$ & \\
$66.7 \%$ abnormal MRI $(n=4)$ & 41.20
\end{tabular}

MRI: magnetic resonance imaging; US: ultrasonography; LFT: liver function test.

$50 \%$ of patients with previous normal ultrasonography. Liver stiffness was high only in a few individuals (1 F3 and 3 F2), but we found an association between higher value of LSM and PHT pointing to the potential role of LSM in PHT screening.

The prevalence of liver disease varies considerably across studies, depending on the diagnostic methods used, from 27 to $35 \%[2,3]$. Our observed prevalence seems higher. It may be explained first by a selection bias in our cohort with only adult patients. Prevalence depends on definition too. For some people, definition may include cirrhosis or PHT, which decreased prevalence to $7 \%$ [2]. Secondly, the rate of prescription of UDCA was slightly higher in patients studied (see Table 1) than in nonincluded patients and also by the imaging technique used to search for lesions. MRI is a technique with high sensitivity and specificity in evaluation of the biliary tract [18]. MRI-based imaging studies in CF are scarce. Durieu et al. showed that, in patients with abnormal liver function tests, clinical abnormalities, and abnormal US, all presented abnormalities on MRI. When all previous explorations were normal, half still had abnormalities on MRI, including cholangiopathy [19]. This confirms the importance of evaluation and MRI in evaluating other techniques, for diagnosis of CFLD. MRI has now become a widely available technique in tertiary reference centers. Moreover, since it is a not radiating method it may be repeated with very few contraindications. We decided not to use contrast agents in these fragile patients to minimize the invasiveness of the examination. In addition, the sequences used for the explorations in question do not necessarily require contrast agents. MRI application in practice seems easy. MRI is also able to diagnose pancreatic abnormalities and we observed pancreatic lesions in the majority of patients. This additional information may contribute to enhancing the impact of MRI on decision-making processes for these patients. Without MRI, 6 out of 25 patients in our series would not have been diagnosed by ultrasonography. This observation further emphasizes the difficulty of diagnosing CFLD. In our study, all patients had steatosis criteria, which is unusual compared to other studies [20]. However, many techniques can help in the diagnosis of steatosis: LB, US, and MRI. These techniques have different efficiencies. So we can explain our low prevalence, by the technique used in this study.

Transient elastography for LSM is a promising tool in the field of hepatology. It has replaced LB in several chronic liver diseases including viral hepatitis [15]. Although it is 
used in current practice, LSM remains to be validated for all cholestatic diseases. As a consequence, there is no correspondence between measures expressed in $\mathrm{kPa}$ and the Metavir scoring system which is proposed for CFLD. Nevertheless, in the present report, we have used thresholds developed in chronic cholestatic diseases considering the pathophysiology to be close [16]. This scoring system has guided clinical practices in order to adapt surveillance and therapeutic options. In addition to being an invasive and potentially dangerous procedure in the presence of respiratory weakness and lung distension, LB has limited reliability, due to the focal distribution of lesions. This often results in under- or overestimation of disease and has led authors to propose dual biopsies in pretransplantation workup.

Transient elastography however obviates this risk and multiple measurements may be appropriate in overcoming underestimation. We chose to apply the "rule of 10 valid measurements" on three sites but it may be worth considering other approaches including increased number of sites of measurement in such clinical conditions.

As others, we found median values of LSM to be quite low. Witters et al. reported a mean of $5.6 \mathrm{kPa}$ in pediatric patients [21] and Kitson et al. reported a mean of $6.55 \mathrm{kPa}$ in 50 unselected adults with CF [22]. In patients with established CFLD, mean LSM reached, respectively, 11.2 in the pediatric cohort [21] and $8.1 \mathrm{kPa}$ in the adult cohort [22]. For cirrhosis, Karlas et al. found a mean of $7,95 \mathrm{kPa}$ [23]. In our study, the mean was 5.7 in all the cohort and was $7.8 \mathrm{kPa}$ for patients with demonstrated liver abnormalities.

It is usual to consider that LSM is a valuable tool to distinguish low fibrosis (F0-F2) and F3-F4. LSM may be a valid approach to screen early CFLD. To do so, cut-off values for CFLD are mandatory. For the first time, Robertson et al. reported a cut-off at $8.83 \mathrm{kPa}$ [20]. Later, Kitson et al. found a cut-off at $6.8 \mathrm{kPa}$ [22]. In our series, we limited assessment of LSM value to its performance in predicting portal hypertension for which no diagnosis controversies exist. We found a cut-off at $6.3 \mathrm{kPa}$. This choice was based on the absence of consensus definition for CFLD outside the field of LB results.

Our results show a link between increased LSM and PHT. This relationship is present even in patients without evidence of cirrhosis. We ruled out cirrhosis in the absence of F4 stage in LSM and in $75 \%$ of patients in the absence of dysmorphic liver feature on MRI. This suggests that noncirrhotic portal hypertension $(\mathrm{NCPH})$ is secondary to other mechanisms. These mechanisms have already been described in primary biliary cirrhosis [24] and primary sclerosing cholangitis [25, 26]. A presinusoidal block has been described in the early stage of primary biliary cirrhosis followed by a sinusoidal block in later fibrosis stages [24]. The main hypothesis is that NCPH is secondary to a vascular component. In $\mathrm{NCPH}$, histopathology reveals nodular regenerative hyperplasia (NRH) and/or obliterative portal venopathy (OPV), responsible for an increase in intrahepatic resistance [26, 27]. In cases of $\mathrm{NRH}$, patients frequently had splenomegaly [28]. OPV can be explained by biliary inflammation-related obliteration of portal veins $[26,29]$. We can speculate that this natural history may be present in CF. In CF, platelets are hyperactive and are responsible for microthrombosis [30]. Early endothelial dysfunction related to CF vasculitis has been described [31]. All of these abnormalities could contribute to OPV. In fact, Witters et al. describe 7 cases of NCPH in CF patients, with presinusoidal block pressure gradient. In biopsy, they found portal branch venopathy [32].

Early treatment of CFLD is of increasing importance in the management of patients with cystic fibrosis and prevention of severe liver damage. CFLD standard treatment is based on UDCA at a dose of $20-30 \mathrm{mg} / \mathrm{kg} /$ day [33]. Immediate treatment upon diagnosis is currently the only proven and effective therapy $[34,35]$. Some studies objectify improved liver function tests and histological damage by UDCA in patients with CFLD. Nevertheless, despite such improvements, there is a lack of evidence for changes in prognosis [33]. An increase in the life expectancy of patients with CF is linked to increased prevalence of CFLD. It is important to optimize disease management prior to lung transplantation or even consider double lung-liver transplant. Currently, none of our patients had transplantation.

\section{Conclusion}

Although it is a retrospective design on a small sample size, our study, based on noninvasive liver explorations using MRI and LSM, provides useful and additional information on assessment of CFLD. The results of such investigations are likely to impact clinical practice justifying further studies. Transient elastography for assessment of liver stiffness may soon play a central role in the noninvasive technique of portal hypertension screening. MRI seems essential for the CFLD diagnosis.

\section{Abbreviations \\ CF: Cystic fibrosis \\ CFLD: Cystic fibrosis-associated liver disease \\ LB: Liver biopsy \\ LSM: Liver stiffness measurement \\ LFT: Liver function test \\ MRI: Magnetic resonance imaging \\ kPa: Kilopascal \\ PHT: Portal hypertension \\ CI: Confidence interval \\ UDCA: Ursodeoxycholic acid.}

\section{Competing Interests}

The authors declare that they have no competing interests.

\section{Authors' Contributions}

C. Lemaitre, E. Billoud, M. Eliezer, M. Quillard, G. Riachi, E. Koning, H. Morisse-Pradier, and H. Montialoux contributed to acquisition of data and drafting of the paper. S. Dominique and C. Savoye-Collet contributed to acquisition of data, drafting of the paper, and critical revision. G. Savoye and O. Goria contributed to drafting of the paper and study supervision. 


\section{Acknowledgments}

The authors are grateful to Nikki Sabourin-Gibbs, Rouen University Hospital, for her help in editing the paper.

\section{References}

[1] R. J. Sokol and P. R. Durie, "Recommendations for management of liver and biliary tract disease in cystic fibrosis," Journal of Pediatric Gastroenterology and Nutrition, vol. 28, no. 1, pp. S1S13, 1999.

[2] C. Colombo, P. M. Battezzati, A. Crosignani et al., "Liver disease in cystic fibrosis: a prospective study on incidence, risk factors, and outcome," Hepatology, vol. 36, no. 6, pp. 1374-1382, 2002.

[3] A. Lindblad, H. Glaumann, and B. Strandvik, "Natural history of liver disease in cystic fibrosis," Hepatology, vol. 30, no. 5, pp. 1151-1158, 1999.

[4] D. Debray, D. Kelly, R. Houwen, B. Strandvik, and C. Colombo, "Best practice guidance for the diagnosis and management of cystic fibrosis-associated liver disease," Journal of Cystic Fibrosis, vol. 10, supplement 2, pp. S29-S36, 2011.

[5] J. A. Cohn, T. V. Strong, M. R. Picciotto, A. C. Nairn, F. S. Collins, and J. G. Fitz, "Localization of the cystic fibrosis transmembrane conductance regulator in human bile duct epithelial cells," Gastroenterology, vol. 105, no. 6, pp. 1857-1864, 1993.

[6] N. Kinnman, A. Lindblad, C. Housset et al., "Expression of cystic fibrosis transmembrane conductance regulator in liver tissue from patients with cystic fibrosis," Hepatology, vol. 32, no. 2, pp. 334-340, 2000.

[7] J. L. Smith, P. J. Lewindon, A. C. Hoskins et al., "Endogenous ursodeoxycholic acid and cholic acid in liver disease due to cystic fibrosis," Hepatology, vol. 39, no. 6, pp. 1673-1682, 2004.

[8] G. A. Ramm, R. W. Shepherd, A. C. Hoskins et al., "Fibrogenesis in pediatric cholestatic liver disease: role of taurocholate and hepatocyte-derived monocyte chemotaxis protein-1 in hepatic stellate cell recruitment," Hepatology, vol. 49, no. 2, pp. 533-544, 2009.

[9] P. J. Lewindon, T. N. Pereira, A. C. Hoskins et al., "The role of hepatic stellate cells and transforming growth factor- $\beta 1$ in cystic fibrosis liver disease," American Journal of Pathology, vol. 160, no. 5, pp. 1705-1715, 2002.

[10] M. R. Narkewicz, "Markers of cystic fibrosis-associated liver disease," Journal of Pediatric Gastroenterology and Nutrition, vol. 32, no. 4, pp. 421-422, 2001.

[11] K. L. Nash, M. E. Allison, D. McKeon et al., "A single centre experience of liver disease in adults with cystic fibrosis 19952006," Journal of Cystic Fibrosis, vol. 7, no. 3, pp. 252-257, 2008.

[12] C. Colombo, P. M. Battezzati, and M. Podda, "Hepatobiliary disease in cystic fibrosis," Seminars in Liver Disease, vol. 14, no. 3, pp. 259-269, 1994.

[13] P. J. Lewindon, R. W. Shepherd, M. J. Walsh et al., "Importance of hepatic fibrosis in cystic fibrosis and the predictive value of liver biopsy," Hepatology, vol. 53, no. 1, pp. 193-201, 2011.

[14] F. Piccinino, E. Sagnelli, G. Pasquale, and G. Giusti, "Complications following percutaneous liver biopsy," Journal of Hepatology, vol. 2, no. 2, pp. 165-173, 1986.

[15] M. Friedrich-Rust, M.-F. Ong, S. Martens et al., "Performance of transient elastography for the staging of liver fibrosis: a metaanalysis," Gastroenterology, vol. 134, no. 4, pp. 960-974, 2008.
[16] C. Corpechot, A. El Naggar, A. Poujol-Robert et al., "Assessment of biliary fibrosis by transient elastography in patients with PBC and PSC," Hepatology, vol. 43, no. 5, pp. 1118-1124, 2006.

[17] World Health Organization, Global Information System on Alcohol and Health (GISAH), World Health Organization, Geneva, Switzerland, 2012, http://www.who.int/globalatlas/default.asp.

[18] J. A. Soto, M. A. Barish, E. K. Yucel, D. Siegenberg, J. T. Ferrucci, and R. Chuttani, "Magnetic resonance cholangiography: comparison with endoscopic retrograde cholangiopancreatography," Gastroenterology, vol. 110, no. 2, pp. 589-597, 1996.

[19] I. Durieu, O. Pellet, L. Simonot et al., "Sclerosing cholangitis in adults with cystic fibrosis: a magnetic resonance cholangiographic prospective study," Journal of Hepatology, vol. 30, no. 6, pp. 1052-1056, 1999.

[20] M. B. Robertson, K. A. Choe, and P. M. Joseph, "Review of the abdominal manifestations of cystic fibrosis in the adult patient," Radiographics, vol. 26, no. 3, pp. 679-690, 2006.

[21] P. Witters, K. De Boeck, L. Dupont et al., "Non-invasive liver elastography (Fibroscan) for detection of cystic fibrosisassociated liver disease," Journal of Cystic Fibrosis, vol. 8, no. 6, pp. 392-399, 2009.

[22] M. T. Kitson, W. W. Kemp, D. M. Iser, E. Paul, J. W. Wilson, and S. K. Roberts, "Utility of transient elastography in the non-invasive evaluation of cystic fibrosis liver disease," Liver International, vol. 33, no. 5, pp. 698-705, 2013.

[23] T. Karlas, M. Neuschulz, A. Oltmanns et al., "Non-invasive evaluation of cystic fibrosis related liver disease in adults with ARFI, transient elastography and different fibrosis scores," PLoS ONE, vol. 7, no. 7, Article ID e42139, 2012.

[24] M. Navasa, A. Parés, M. Bruguera, J. Caballería, J. Bosch, and J. Rodés, "Portal hypertension in primary biliary cirrhosis. Relationship with histological features," Journal of Hepatology, vol. 5, no. 3, pp. 292-298, 1987.

[25] S. C. Abraham, P. S. Kamath, B. Eghtesad, A. J. Demetris, and A. M. Krasinskas, "Liver transplantation in precirrhotic biliary tract disease: portal hypertension is frequently associated with nodular regenerative hyperplasia and obliterative portal venopathy," American Journal of Surgical Pathology, vol. 30, no. 11, pp. 1454-1461, 2006.

[26] I. R. Wanless, "Micronodular transformation (nodular regenerative hyperplasia) of the liver: a report of 64 cases among 2,500 autopsies and a new classification of benign hepatocellular nodules," Hepatology, vol. 11, no. 5, pp. 787-797, 1990.

[27] S. Hillaire, E. Bonte, M.-H. Denninger et al., "Idiopathic noncirrhotic intrahepatic portal hypertension in the West: a reevaluation in 28 patients," Gut, vol. 51, no. 2, pp. 275-280, 2002.

[28] F. Colina, F. Pinedo, J. A. Solís, D. Moreno, and M. Nevado, "Nodular regenerative hyperplasia of the liver in early histological stages of primary biliary cirrhosis," Gastroenterology, vol. 102, no. 4, pp. 1319-1324, 1992.

[29] T. Roskams, A. Baptista, L. Bianchi et al., "Histopathology of portal hypertension: a practical guideline," Histopathology, vol. 42, no. 1, pp. 2-13, 2003.

[30] B. P. O'Sullivan, M. D. Linden, A. L. Frelinger III et al., "Platelet activation in cystic fibrosis," Blood, vol. 105, no. 12, pp. 46354641, 2005.

[31] A. Šedivá, J. Bartůňková, J. Bartošová, C. Jennette, R. J. Falk, and H. S. Jethwa, "Antineutrophil cytoplasmic antibodies directed against bactericidal/permeability-increasing protein detected in children with cystic fibrosis inhibit neutrophil-mediated killing of Pseudomonas aeruginosa," Microbes and Infection, vol. 5, no. 1, pp. 27-30, 2003. 
[32] P. Witters, L. Libbrecht, T. Roskams et al., "Noncirrhotic presinusoidal portal hypertension is common in cystic fibrosisassociated liver disease," Hepatology, vol. 53, no. 3, pp. 10641065, 2011.

[33] K. Cheng, D. Ashby, and R. Smyth, "Ursodeoxycholic acid for cystic fibrosis-related liver disease," Cochrane Database of Systematic Reviews, no. 2, Article ID CD000222, 2000.

[34] C. Colombo, P. M. Battezzati, M. Podda et al., "Ursodeoxycholic acid for liver disease associated with cystic fibrosis: a doubleblind multicenter trial. The Italian Group for the Study of Ursodeoxycholic Acid in Cystic Fibrosis," Hepatology, vol. 23, no. 6, pp. 1484-1490, 1996.

[35] C. Colombo, M. C. Russo, L. Zazzeron, and G. Romano, "Liver disease in cystic fibrosis," Journal of Pediatric Gastroenterology and Nutrition, vol. 43, no. 1, pp. S49-S55, 2006. 


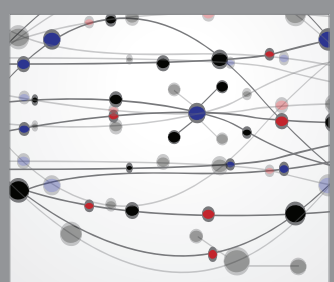

The Scientific World Journal
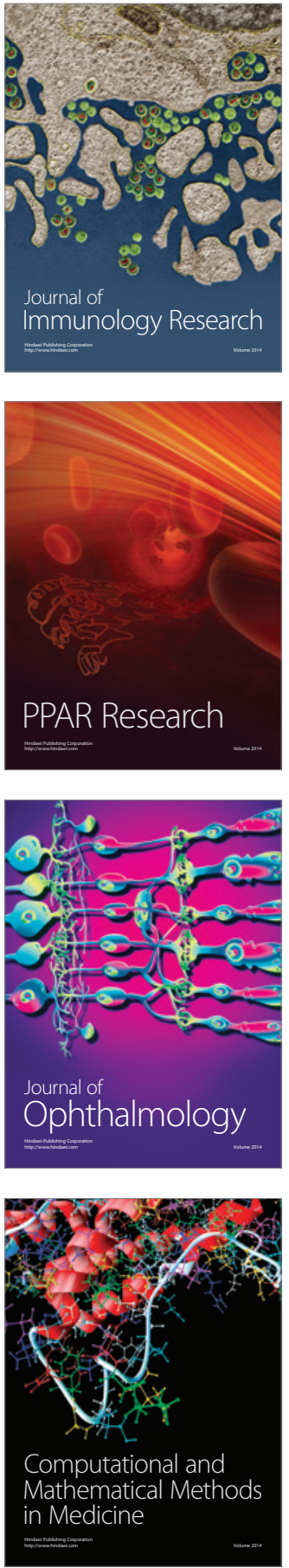

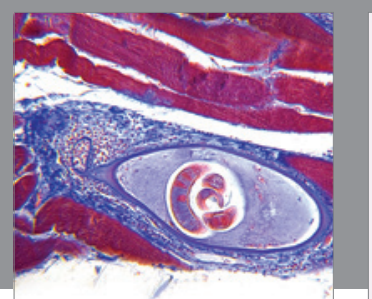

Gastroenterology Research and Practice

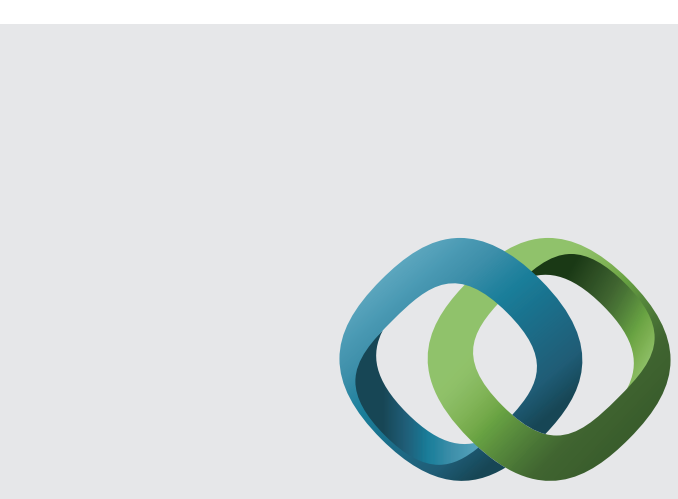

\section{Hindawi}

Submit your manuscripts at

http://www.hindawi.com
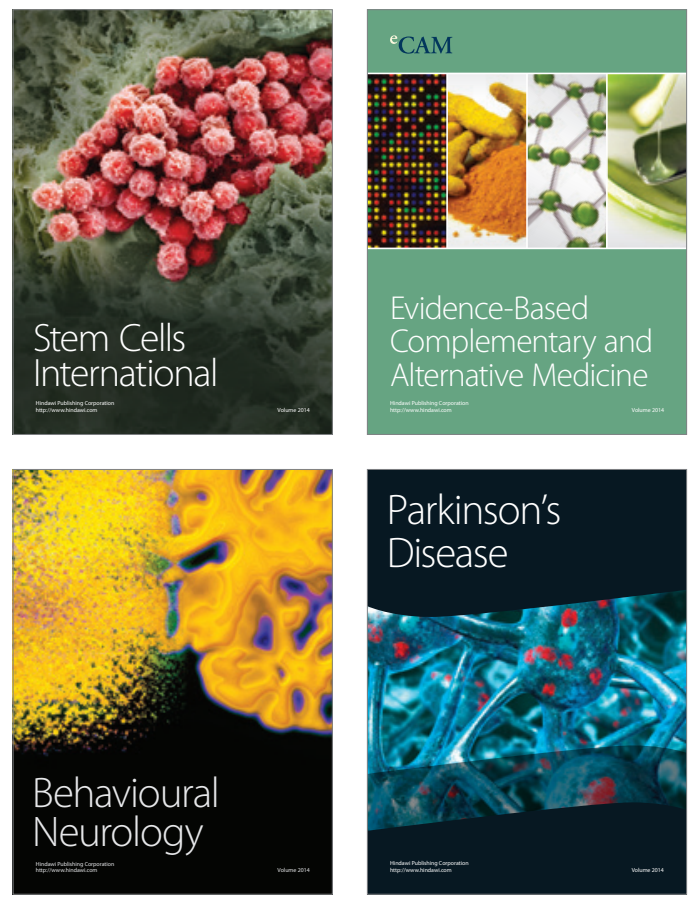
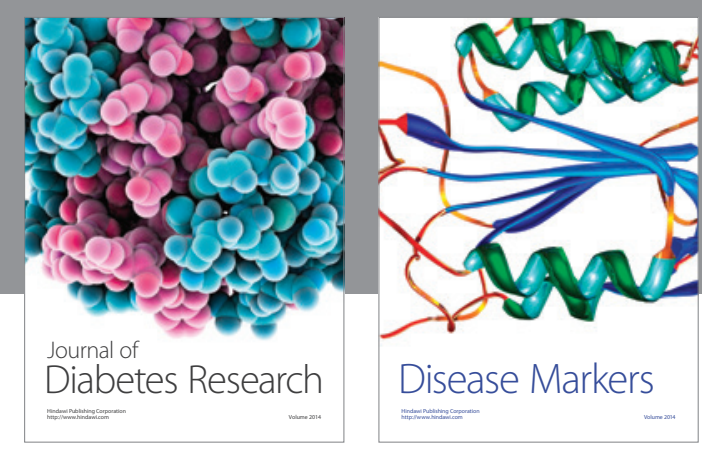

Disease Markers
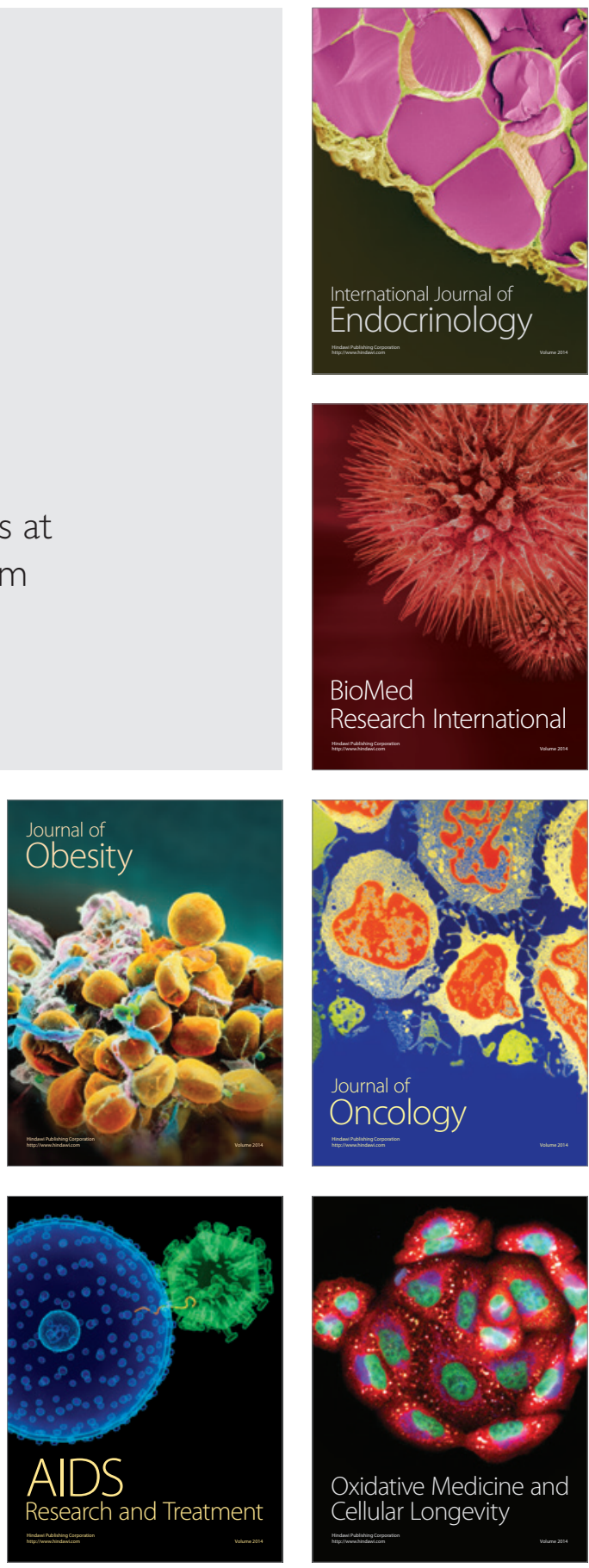